\title{
RESEARCH
}

\section{Double dislocations in a single digit: a Canadian perspective}

\author{
Joseph P. Corkum MD, Kevin Calder MD, Justin L. Paletz MD \\ Division of Plastic and Reconstructive Surgery, Faculty of Medicine, Dalhousie University
}

\begin{abstract}
Dislocation of both joints in the same digit due to a single insult is rare. To date there have been no reported cases from Canada. The purpose of our study is to review the literature and to survey plastic surgeons about this injury. We have contributed two case reports as well. Within six months, two patients presented to the Halifax Infirmary plastic surgery clinic for management of a double dislocation of a single digit. A comprehensive literature review of the English and non-English literature was performed. Additionally, a survey on experiences with double dislocations was developed and distributed to Plastic Surgeons practicing in Canada. 61 reported cases were identified in the literature, none of which were treated in Canada. 76\% of cases were reported in English with the remaining 24\% of cases reported in a non-English language (German, French). One hundred of the 373 members of the Canadian Society of Plastic Surgeons contacted replied (27\%). Fourteen had previously encountered a double dislocation of a single digit. This injury was treated with closed reduction $90 \%$ of the time and splinting (65\%) for two to three weeks. All patients regained normal range of motion with the exception of one. Ninety-three and $85 \%$ favored closed reduction and splinting, respectively. Two weeks was the preferred immobilization period $(36 \%)$. We present the first reported cases of double dislocation of a single digit in Canada. We outline the etiology of this rare injury, previous treatments employed, and potential pitfalls encountered. The authors recommend a preferred treatment strategy for the management of double dislocation of a single digit.
\end{abstract}

Q uantifying the epidemiology of finger joint dislocations is not a trivial task. Likely underreported, an article by Brinker et al. quantified it based on orthopaedic referrals. Over a period of time, represented as 1000 member life-years, they found a rate of 0.059 for hand dislocations. ${ }^{1}$ A finger dislocation can be caused by hyperextension, hyperflexion, lateral deviation, torsion, or impaction. ${ }^{2}$ When medical care is sought for a finger dislocation, reduction and a period of immobilization is often the extent of necessary treatment. ${ }^{3}$ Much less common however, is an injury in which both joints in a finger are essentially simultaneously dislocated (Figure 1). Therefore, the epidemiology is harder still to elucidate and treatments are not easily correlated with results. Bartels et al. reported the first incidence of such an injury in 1874 and a limited number of case reports and reviews have followed since. ${ }^{4}$ There have been no cases of double dislocations in a single digit reported from Canada to date.

Two cases of double dislocations presented to the Halifax Infirmary within a short period of time. Each case was treated similarly, although a paucity of available literature was available for guidance. The purpose, therefore, of this article was to review the literature and to survey plastic surgeons practicing in Canada on their experiences with double dislocations. Additionally, we report on the two cases of patients with this rare injury.

\section{Methods}

A literature review of the English and non-English language literature was conducted. Non-English language articles were translated to English for

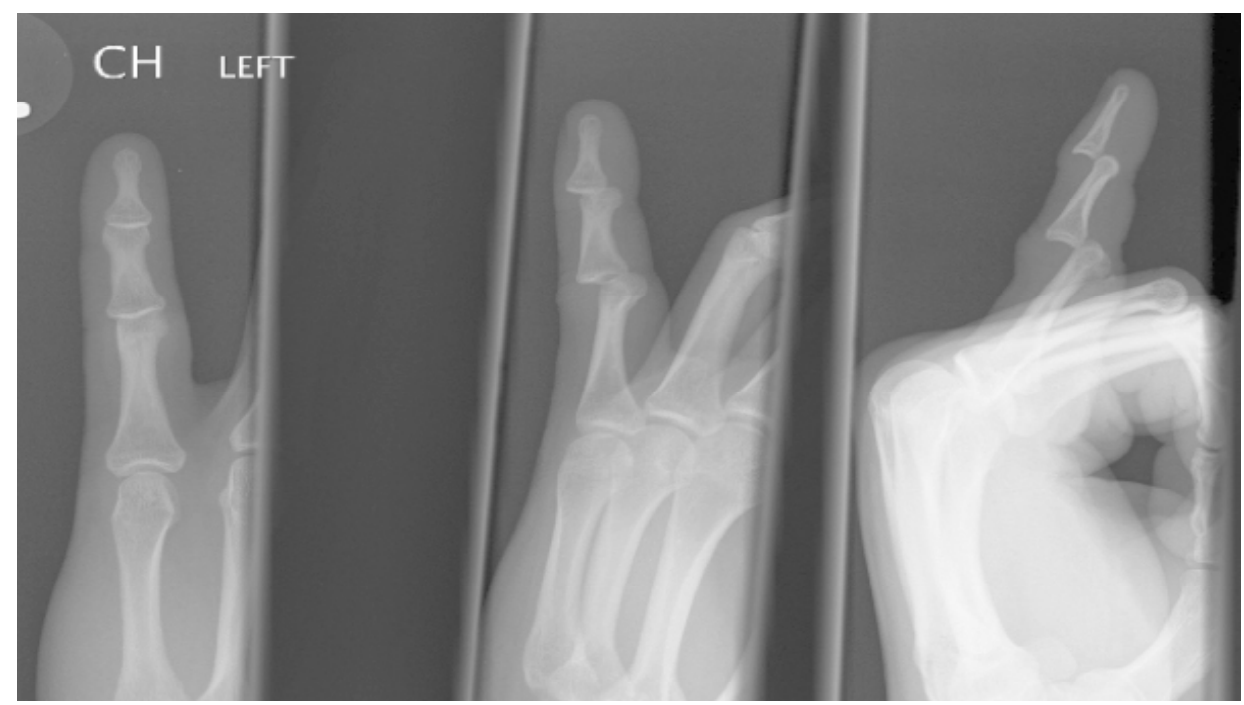

Figure I. Example X-rays of double dislocations in a single digit. 
inclusion in the study.

The review was conducted by searching the literature databases on Medline and the Cochrane Library for relevant articles published before June 2015. The search strings used were "double dislocation" and "simultaneous dislocation." The inclusion criterion was double dislocations of a single digit from a single insult. Reports were excluded if they pertained to the thumb, included a metacarpophalangeal dislocation (which excludes triple dislocations), or the injury was managed surgically. Each English title and abstract was scanned by one of the authors [JC] and compared with the inclusion and exclusion criteria. The same was done for non-English articles by another author [KC]. After inclusion, the bibliography of each article was searched for other potential studies.

The following was extracted from each selected article and used for this review: author, year, sample size of each group, study model, follow-up duration, study results, and author's recommendations. The results of the studies were qualitatively assessed. For the purpose of this study, primary outcome measures were range of motion and complication rates. A normal range of motion was defined as 110 degrees of flexion at the proximal interphalangeal (PIP) joint and 90 degrees at the distal interphalangeal (DIP) joint, as per Mathes. ${ }^{5}$

\section{Survey}

A survey was developed and distributed to plastic surgeons practicing in Canada registered with the Canadian Society of Plastic Surgeons (CSPS). The purpose was to establish how common the injury is in Canada, how it has been treated in the past, and how members of the CSPS would treat it if encountered in the future. The survey was facilitated by Opinio software, which is a third-party survey-administering service that was accessed through our local institution, Dalhousie University. Using Opinio, each CSPS member was contacted to complete the survey. The email subject used was "Have you seen this injury?" with the intent of creating curiosity and increasing the completion rate. After two weeks the survey was resent. The survey was available for a total duration of 3 weeks. Any completed surveys were returned to Opinio, which anonymized the information and provided results.

\section{Results}

\section{Literature Review}

A total of 67 reported cases were identified in 41 retrieved articles, none of which were Canadian. Thirty-two (78\%) of the articles were reported in English $^{6-37}$ and the remaining nine (22\%) were reported in a non-English language (5 French, 4 German). ${ }^{38-46}$

The little finger was the most affected finger, with
37 (55\%) total cases. The ring finger, long finger, and index finger had 13 (19\%), 4 (6\%), and 4 (6\%) reported cases, respectively. The remaining cases did not report the affected digit. Of the 67 reported cases, 46 patients (68\%) had their hand splinted following reduction of the dislocations. Buddy taping was used to treat 10 (15\%) cases, and the rest of the patients were either casted or the authors did not specify.

In 42 cases $(63 \%)$ the patient ultimately regained full painless range of motion with the affected finger. However, 18 patients (27\%) were left with range of motion (ROM) deficits and three patients (4\%) had to undergo procedures because of complication (joint instability and severe pain). ${ }^{6,19,35}$ All of these reports that included comments on patient function indicated that patients were fully functional despite their ROM deficits. In the remaining cases the authors did not specifically comment on follow up or outcomes.

\section{Survey}

Of the 373 members of the CSPS contacted, 100 responded for an overall response rate of $27 \%$. Of the surgeons that responded to the survey, 14 had previously encountered a double dislocation of a single digit. The 14 double dislocations were encountered between the years 1985 to 2011, and had been seen by staff (9), fellows (2) and residents (3) alike.

Of the 14 cases, $90 \%$ were treated with closed reduction, and $65 \%$ were given a splint. The surgeons that described the splinting all indicated that slight PIP and DIP flexion was used for approximately two to three weeks. Only one surgeon reported a less than ideal outcome, which was a minimally limited range of motion at follow up.

In the hypothetical case portion of the survey, $93 \%$ of respondents indicated they would use a closed reduction over open reduction. Eighty five percent of surgeons said they would use a splint and 15\% said they would use a K-wire to treat the injury. Of the $85 \%$ who indicated that they would use a splint, 59\% said they would put the PIP and DIP into slight flexion, $27 \%$ the position of safety, and 10\% would use buddy taping. The remaining $4 \%$ described an option falling outside of these broad categories, such as putting the PIP in flexion and the DIP in extension. Two weeks was the most popular option for number of weeks of immobilization, although there was marked variability (Figure 2).

\section{Case \#1}

In October 2008, a 17-year-old right hand dominant male presented to the local Plastic Surgery clinic. He had sustained a double dorsal dislocation of the distal and proximal interphalangeal joints in his left little 


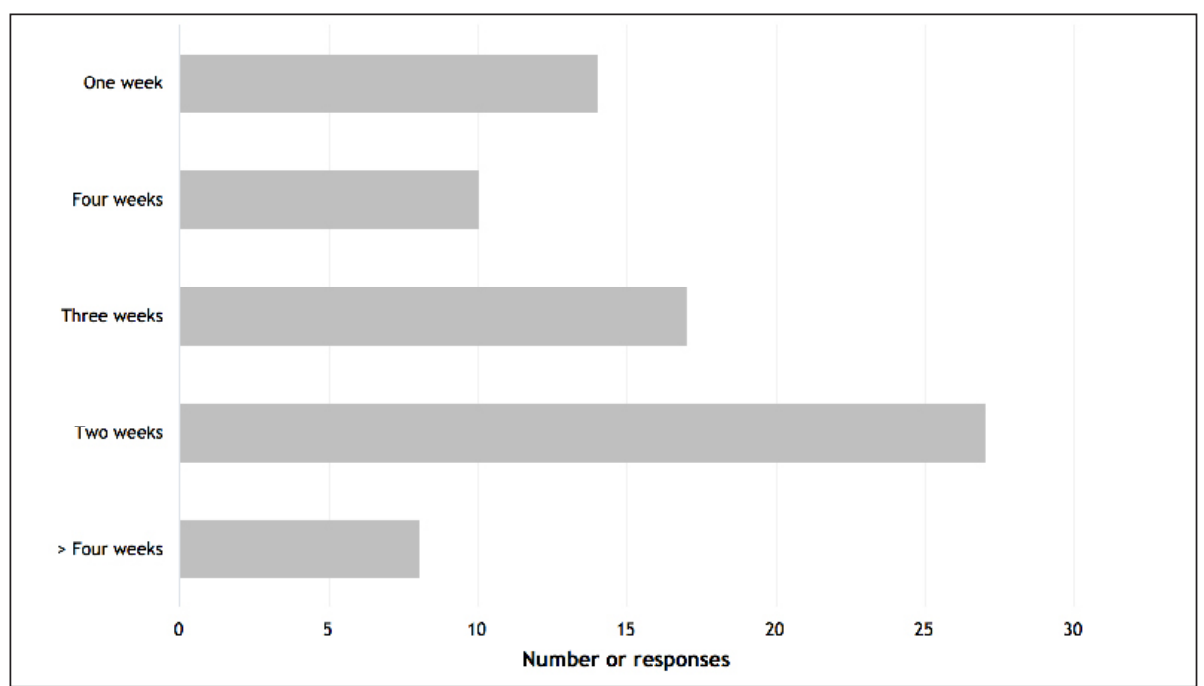

Figure 2. Surveyed surgeons' response to the question "For how long would you splint this injury?" This was asked after outlining a hypothetical case of double dislocation.

finger. In addition, he also had a small volar plate avulsion fragment at the base of the middle phalanx. The injury occurred while playing basketball.

The diagnosis was made by X-ray. He had had his injury reduced at a peripheral hospital, and during the clinic visit the finger was buddy-taped to the ring finger for a recommended two-week period. At the one month follow-up appointment, the patient reported that he was only adherent to two days of buddy taping. On physical exam residual swelling remained over the PIP joint, and it was slightly bruised and tender in the area as well. Flexion was limited, but he was able to achieve nearly full extension. The patient was referred to physiotherapy to continue improving his functional outcome. He was then lost to follow up.

\section{Case \#2}

In November of the same year a 16-year-old right hand dominant male was seen for a dorsal dislocation of both the DIP and PIP joints in his right little finger. In this case there was no associated avulsion fragment or fracture. The injury was sustained while playing volleyball. The diagnosis was made by X-ray. His finger was also reduced at a peripheral hospital, and at the clinic visit his finger was buddy-taped to the ring finger for a recommended two weeks. This patient also was only adherent with a short period of buddy taping (one day), and at a day nine follow-up appointment the buddy taping was redone. At greater than two months follow up, the patient had full flexion, but there was 30 degrees of flexion contracture at the PIP joint. He reported that tenderness had been decreasing over time, and he was further instructed on exercises to reduce the contracture. He was then lost to follow up.

\section{Discussion}

Double dislocation of a single digit has an exceedingly low incidence, which is primarily a reflection of its etiology. For a double dislocation to occur, the distal phalanx is struck by a force that causes the DIP joint to dislocate dorsally. The force is of such a magnitude that it is not fully dissipated in the DIP joint and is therefore transmitted to the PIP joint with sufficient remaining energy to cause an additional dorsal dislocation. For this to occur, the force must strike the palmar distal phalanx within a limited range of potential angles, which fall between parallel and perpendicular with the digit, but cannot approach either. There is general agreement on this mechanism in the literature. ${ }^{13}$

Treatment of this injury did not differ substantially between the literature and surveyed members of the CSPS. Patients were usually managed with a splint, and common positions for splinting were the intrinsic plus and position of safety. The second most popular treatment option was buddy taping to an adjacent digit. Two weeks was the most common length of immobilization, and early mobilization was frequently encouraged.

In the literature, $4 \%$ of patients ultimately had to be managed surgically because conservative management failed. These patients suffered complications, which were related to pain and recurrent dislocations. One patient had been splinted, and one had been buddy taped. It is difficult to make conclusions from these two isolated cases, but important to recognize that complications are a possibility following this injury. ${ }^{6,19}$

Of the 14 cases recorded in the survey, only one (7\%) had an unsatisfactory outcome. This is in contrast to the literature review, which showed $27 \%$ of patients had residual deficits in ROM. This difference is likely explained by the much lower sample in the survey results, but could also be due to a recall bias, which is intrinsic to the retrospective survey. Surgeons were asked to remember if they had seen the injury, and how they treated it. In at least one case the injury had occurred 27 years previously, so there may have been 
difficulties recounting case details. Many surgeons commented following the survey that the hypothetical case was restrictive in options.

This limitation tended to constrain responses, but it was necessary to make the options discrete to allow for quantitative results.

The review was limited by the quality of studies. Very few studies included were higher than level 4 case reports, and none were higher than level 3 research. Therefore, making definitive conclusions is precluded based on the level of quality of articles available for review. The survey was limited by recall bias, and the potential for a single case being reported by different care providers. However, amalgamating the information from each component of this study, the authors recommend treating double dislocations of a single digit with a closed reduction, followed by splinting or buddy taping to an adjacent digit for a period of two weeks. The finger should be in the position of safety or with slight flexion in both the DIP and PIP joints. An injury more complex than two simple dislocations however warrants consideration of alternative management strategies. Many survey comments pointed out that an unstable reduction is important to recognize. Follow up is necessary, and residual ROM deficits are the most common complication. Early mobilization should be encouraged to help alleviate the incidence of complication, however they commonly did not affect patient function.

\section{References}

1. Brinker MR, O'Connor DP. The incidence of fractures and dislocations referred for orthopaedic services in a capitated population. J Bone Joint Surg Am 2004;86(2):290-7.

2. Thorne C, Grabb WC, Beasley RW. Grabb and Smith's Plastic Surgery. Lippincott Williams \& Wilkins, 2007. Chapter 81: Fractures, Dislocations and Ligamentous injuries of the Hand.

3. Jones NF, Jupiter JB, Lalonde DH. Common fractures and dislocations of the hand. Plast Reconstr Surg 2012;130(5):722e-36e.

4. Bartels M. Traumatische luxationen. Arch Klin Chir 1874;16:636-54.

5. Mathes S. Plastic Surgery. Saunders, 2005. Chapter 1: Anatomy and biomechanics of the hand.

6. Bayne O, Chabot JM, Carr JP, Evans EF. Simultaneous dorsal dislocation of interphalangeal joints in a finger. Clin Orthop Relat Res 1990;(257):104-6.

7. Charalambous CP, Rajkumar P, Samarji R. Double dislocation of the proximal and distal interphalangeal joints of the little finger. Int J Clin Pract 2002;56(10):816.

8. Curran AJ, McKiernan MV, McCann J. Double interphalangeal joint dislocation in a little finger. Injury 1993;24(2):138.

9. Espinosa RH, Renart IP. Simultaneous dislocation of the interphalangeal joints in a finger: case report. J Hand Surg Am 1980;5(6):617-8.

10. Hage JJ, Reinders JF, Schuwirth L. Simultaneous dislocation of both interphalangeal joints in a finger. Arch Orthop Trauma Surg 1990;109(3):179-80.

11. Hara K, Uchiyama S, Kato H. Irreducible simultaneous dislocation of both interphalangeal joints in the little finger: a case report. Hand Surg 2009;14(1):39-42.

12. Hardy I, Russell J, MacFarlane I. Simultaneous dislocation of the interphalangeal joints in a finger. J Trauma 1985;25(5):450-1.

13. Hutchison JD, Hooper G, Robb JE. Double dislocations of digits. J Hand Surg Br 1991;16(1):114-5.

14. Ikpeme JO. Dislocation of both interphalangeal joints of one finger. Injury 1977;9(1):68-70.
15. Inoue G, Kino Y, Kondo K. Simultaneous dorsal dislocation of both interphalangeal joints in a finger. Am J Sports Med 1993;21(2):323-5

16. Kalakoti RR, Monga P. Double dislocation of little finger in nonathletic person. J Trauma 2007;62(3):786.

17. Kim YS, Song HS, Kim HM, Chung E, Park IJ. Simultaneous double dislocation of the interphalangeal joint in a finger. Arch Orthop Trauma Surg 2009;129(10):1387-90.

18. Konsens RM, Cohn BT, Froimson AI. Double dislocation of the fifth finger. Orthopedics 1987;10(7):1061-2.

19. Krebs B, Gron LK. Simultaneous dorsal dislocation of both interphalangeal joints in a finger. Br J Sports Med 1984;18(3):217-9.

20. Krishnan SG. Double dislocation of a finger: case report. Am J Sports Med 1979;7(3):204-5.

21. Loupasis G, Christoforakis J, Aligizakis A. Simultaneous double interphalangeal dislocation in a finger. J Orthop Trauma 1998;12(1):702 .

22. Mesmar MA. Double dislocation of the interphalangeal joints in the finger. Saudi Med J 2000;21(5):493-4.

23. Nathan FF, Schlein AP. Multiple dislocations of a single finger. Hand 1973;5(1):52-4.

24. Rajoo RD, Govender S, Goga IE. Simultaneous dislocation of the interphalangeal joints: a report of 2 cases. S Afr Med J 1990;77(1):45-6.

25. Ron D, Alkalay D, Torok G. Simultaneous closed dislocation of both interphalangeal joints in one finger. J Trauma 1983;23(1):66-7.

26. Soucacos PN, Beris AE, Malizos KN, Zoubos AB. Two-level dorsal dislocation of the little finger. Am J Orthop 1996;25(12):839-41.

27. Takami H, Takahashi S, Ando M. Simultaneous double interphalangeal dislocation in one finger. Arch Orthop Trauma Surg 2000;120(5 6):361-2.

28. Terndrup TE, Schreck DM. Simultaneous dorsal dislocation of the proximal and distal interphalangeal joints in one digit. Ann Emerg Med 1988;17(4):368-70.

29. Van Ransbeeck H, De Smet L. Double dislocation of both interphalangeal joints in the finger. Case report and literature review. Acta Orthop Belg 2004;70(1):72-5.

30. Watson FM. Simultaneous interphalangeal dislocation in one finger. J Trauma 1983;23(1):65.

31. Weseley MS, Barenfeld PA, Eisenstein AL. Simultaneous dorsal dislocation of both interphalangeal joints in a finger: case report. J Bone Joint Surg Am 1978;60(8):1142.

32. Andersen MB, Johannsen H. Double dislocation of the interphalangeal joints in the finger: case report and review of publications. Scand J Plast Reconstr Surg Hand Surg 1993;27(3):233-6.

33. Kligman M, Roffman M. Simultaneous dislocation of both interphalangeal joints and flexor tendon tear in a finger. Injury 1998;29(3):246-7.

34. Fu LJ, Dai KR. Simultaneous double dislocation of the interphalangeal joint in one finger. Chin Med J 2013;126(5):974-5.

35. Mishra PK, Gupta A, Chandra GS. Unusual double dislocation of both joints in a same finger: a case report. Iran Red Crescent Med J 2013;15(11):e9989.

36. Seki Y. Simultaneous double dislocation of the interphalangeal joint of the same finger: a report of two cases. Pan Afr Med J 2014;19:400.

37. Uysal MA, Akcay S, Ozturk K. Simultaneous double interphalangeal joints dislocation in a finger in a teenager. J Clin Orthop Trauma 2014;5(2):107-9.

38. Alonso De Ros JF, Proubasta IR, Dolz Jordi C, Mir Bullo X. Simultaneous luxation of proximal and distal interphalangeal joints of the fingers. Ann Chir Main 1987;6(1):43-7

39. Kofuncu OA, Scheer H, Raschke E. Double simultaneous dislocation of a 3-jointed finger. Based on 2 cases. Chirurg 1985;56(11):749-50.

40. Mahlfeld A, Weber K. The interesting case: double dislocation of one finger. Handchir Mikrochir Plast Chir 1995;27(1):49-50.

41. Michel J, Asselineau A, Aboufarah F, Nguyen-Duy T. Simultaneous dislocation of the interphalangeal joints of the index finger. Rev Chir Orthop Reparatrice Appar Mot 2003;89(6):558-61.

42. Pestessy J. Simultaneous dislocation of both shoulder joints. Magy Traumatol Orthop Helyreallito Seb 1982;25(2):145-6.

43. Rouanet T, Ramboaniana S, Leclere F, Berger M. Double dislocation of the interphalangeal joints of the little finger, a report of two cases. Chir Main 2009;28(5):314-7.

44. Stock HJ, Weber H. Double dislocation on one finger. Beitr Orthop Traumatol 1974;21(12):746-7.

45. Tabib W, Sayegh S, Frick M, Ninkabou Y, Meyer M. Simultaneous traumatic dislocations of the index finger: apropos of a case with review of the literature. Rev Chir Orthop Reparatrice Appar Mot 1998;84(1):75-8.

46. Zrig M, Ammari T, Annabi H, Cherif R, Trabelsi M, M'Barek M, et al. Simultaneous proximal and distal interphalangeal joint dislocation on the same digit. Tunis Med 2008;86(12):1097. 